\title{
EDUCAÇÃO AMBIENTAL, SUSTENTABILIDADE E RECICLAGEM: RELATO DE UMA EXPERIÊNCIA PEDAGÓGICA REALIZADA COM ALUNOS DO ENSINO FUNDAMENTAL
}

\author{
Natália Lampert Batista* \\ Ângela Renata Kraisig** \\ Luccianne Guedes da Luz Martins ${ }^{* * *}$
}

Resumo: A Educação Ambiental surge com a possibilidade de um novo olhar sobre o mundo e, consequentemente, como uma forma de debate interdisciplinar acerca das realidades e dos conteúdos programáticos das diferentes disciplinas. A partir disso, teve-se como objetivo geral desenvolver práticas interdisciplinares nas disciplinas de Ciências, de Geografia e de História, frente à temática ambiental relacionada às tecnologias reutilizáveis, inclusivas e interativas. A partir dessas premissas, os alunos dos $7^{\circ}$ anos, da EMEF Junto ao CAIC Luizinho de Grandi, desenvolveram pesquisas atreladas a temática tecnologia, ciência e sustentabilidade aplicadas à reciclagem e construíram materiais que foram expostos e premiados ( $3^{\circ}$ lugar) na III Feira Municipal de Ciência, Tecnologia e Sustentabilidade, realizada pela Prefeitura Municipal de Santa Maria/RS, no ano de 2017. As atividades desenvolvidas contribuíram com a discussão ambiental na Escola, bem como para a promoção de pesquisas de iniciação científica pelos estudantes de Ensino Fundamental, despertando o interesse pela compreensão da realidade do lugar e pela pesquisa, bem como estimulando o senso crítico e a cidadania.

Palavras-chave: Interdisciplinaridade. Ambiente. Tecnologia. Sustentabilidade. Reciclagem.

\section{Contextualização inicial}

A Educação Ambiental surge com a possibilidade de um novo olhar sobre o mundo e sobre o lugar onde os educandos vivem e estudam e, consequentemente, como forma de debate interdisciplinar acerca das realidades e dos conteúdos programáticos das diferentes disciplinas que compõem o currículo escolar. Pode ser definida como "a ação educativa permanente pela qual a comunidade toma consciência da realidade global, do tipo de relações que os homens

\footnotetext{
* Doutoranda em Geografia pela Universidade Federal de Santa Maria (UFSM) e Professora de Geografia na Escola Municipal de Ensino Fundamental Junto ao CAIC Luizinho de Grandi, Santa Maria/RS.

* Doutoranda em Educação em Ciências: Química da Vida e Saúde pela Universidade Federal de Santa Maria (UFSM) e Professora de Ciências na Escola Municipal de Ensino Fundamental Junto ao CAIC Luizinho de Grandi (até dez/2017), Santa Maria/RS.

Doutoranda do curso de Museologia pela Universidade Lusófona de Humanidades e Tecnologias de Lisboa e Professora de História na Escola Municipal de Ensino Fundamental Junto ao CAIC Luizinho de Grandi, Santa Maria/RS.
} 
estabelecem entre si e com a natureza, dos problemas derivados dessas relações e das suas causas profundas" (TEITELBAUM, 1978 citado por GAUDIANO, 2005, p. 34) e, portanto, não deve ser compreendida pelo prisma de uma única ciência, mas pelos múltiplos olhares e objetos do saber.

A temática ambiental é evidenciada pelas Diretrizes Curriculares Nacionais (DCNs) para a Educação Ambiental que destacam o compromisso das instituições educacionais com o papel "socioeducativo, ambiental, artístico, cultural e as questões de gênero, etnia, raça e diversidade que compõem as ações educativas, a organização e a gestão curricular são componentes integrantes dos projetos institucionais e pedagógicos da Educação Básica e da Educação Superior" (BRASIL, 2012, p. 30).

E, desse modo, torna a Educação Ambiental tarefa de todos os educadores em todas as disciplinas. Logo, pode-se olhar o ambiente a partir da disciplina de Ciências com o estudo ecológico, da Geografia pelas constituições do entendimento, estudo do espaço geográfico e suas influências nos processos ambientais e da História pela compreensão dos fatos que contribuem para isso, por exemplo. Cada sujeito e cada disciplina enxerga com os seus olhos e compreende a partir de onde os seus pés pisam (BOFF, 2004), porém a união desses olhares permite um entendimento mais complexo da realidade, estimulando o pensamento crítico e reflexivo sobre o ambiente e rompendo com a visão dualista sobre o mesmo como propõe Achkar, Domínguez e Pesce (2007).

Além disso, alguns documentos, como no caso, os Parâmetros Curriculares Nacionais (PCNs), já vem orientando professores a utilizarem tais temas no ensino. Alguns temas sugeridos neste documento foram: saúde, ambiente, pluralidade cultural, ética, orientação sexual, trabalho e consumo (FERREIRA; WORTMANN, 2017). É válido destacar, que os temas mencionados são considerados "pertinentes" a diferentes disciplinas escolares, ou seja, as suas abordagens não deve ser restrita a uma única disciplina, mas sim, devem se dar pelo conjunto de disciplinas.

Além disso, os PCNs orientam para que tais temas sejam tratados na área de Ciências (mesmo que não exclusivamente nessa área de conhecimento), e recomendam que os cuidados com o ambiente não se limitem ao estudo da flora e da fauna existentes, mas envolvam modos de preservação ambiental (Educação Ambiental) (FERREIRA; WORTMANN, 2017). No que tange a Geografia, a temática ambiental está estritamente ligada ao seu objeto de estudo: o espaço geográfico, porque ele se ocupa da relação sociedade-natureza e, portanto, as questões ambientais são intrínsecas a abordagem geográfica. Quanto a História, pode contribuir com o entendimento 
do processo que gerou determinado fato ambiental. Dessa forma, tanto a disciplina de Ciências como a de Geografia e a de História se veem desafiadas a pensarem a temática ambiental de forma conjunta e integrada, resultando em novos olhares para o mundo em que vivemos e, consequentemente, em uma busca constante por uma "nova ética ambiental".

Frente a essa necessidade de debater o ambiente nas múltiplas áreas e a busca por uma “nova ética ambiental”, Junges (2010) menciona ser imprescindível uma mutação cultural capaz de superar a visão simplista da modernidade, integrando olhares em prol da construção de conhecimentos complexos e abrangentes sobre o ambiente. Trata-se da passagem de um reducionismo científico-metodológico, que fragmenta a natureza para estudá-la e conhecê-la, a uma cultura sistêmica que compreende as inter-relações presentes no ambiente por meio de uma visão interdisciplinar e totalizante.

De forma similar, Maria Novo (2007) ressalta ser necessário pensar glocalmente, isto é, global e localmente ao mesmo tempo e não escolher apenas uma escala de análise. Desse modo, conforme Batista, Ziemann e Prina (2018) somente uma Educação Ambiental crítica e bem articulada com a realidade e com as vivências dos estudantes, permite um pensar mais crítico, reflexivo e ético sobre o Planeta Terra. A Educação Ambiental deve, de maneira geral, impulsionar um pensamento criativo e perseverante, a partir das suas quatro dimensões sustentáveis (Quadro1), além de servir como mecanismo para compreender a complexidade dos processos naturais e sociais e das dinâmicas interacionais que conflitam em diversas realidades socioambientais.

Quadro 1 - Incorporação da sustentabilidade através de diferentes dimensões na Educação Ambiental.

\begin{tabular}{|c|c|c|}
\hline \multicolumn{2}{|c|}{ INCORPORAÇÃO DA SUSTENTABILIDADE ATRAVÉS DE DIFERENTES } \\
DIMENSÕES NA EDUCAÇÃO AMBIENTAL
\end{tabular}

Fonte: Achkar, Domínguez e Pesce (2007) adaptado por Batista, Ziemann e Prina (2018, p. 172). 
Segundo Dotto (2016, p. 27):

\begin{abstract}
A Educação Ambiental deve ser uma prática atitudinal e procedimental, pois além de instigar o aluno a participar e envolver-se em determinado tema ligado ao meio ambiente, proporciona mudanças de comportamentos e estimula a cidadania por intermédio da participação social. Assim, favorece transformações de uma realidade em relação aos problemas ambientais, além de envolver todos os alunos, professores e comunidade escolar.
\end{abstract}

Partindo das presentes premissas, pensou-se o projeto "Ações interdisciplinares alusivas ao ambiente na EMEF Junto ao CAIC Luizinho de Grandi” aqui descrito e inscrito na III Feira Municipal de Ciência, Tecnologia e Sustentabilidade, realizada pela Prefeitura Municipal de Santa Maria, em 24 de novembro de 2017. O objetivo geral do trabalho foi desenvolver práticas interdisciplinares nas disciplinas de Ciências, de Geografia e de História, frente à temática ambiental relacionada às tecnologias reutilizáveis, inclusivas e interativas.

Especificamente, objetivou-se:

a) Sensibilizar os alunos frente à problemática do ambiente no espaço local;

b) Gerar ações de envolvimento e pesquisa dos alunos desenvolvendo noções de responsabilidade frente à comunidade e o espaço escolar;

c) Trabalhar com os alunos conhecimentos relacionados à Ciência, à Geografia e à História que envolvessem a interface tecnologia, ciência e sustentabilidade aplicadas à Reciclagem;

d) Desenvolver a criatividade dos alunos a partir de ações cidadãs.

As práticas pedagógicas relatadas foram desenvolvidas na EMEF Junto ao CAIC Luizinho de Grandi que está localizada na Zona Administrativa Sul de Santa Maria/RS, no Bairro Lorenzi como apresentada na Figura 1. 
Figura 1 - Mapa de localização da Escola Municipal de Ensino Fundamental J/AO CAIC "Luizinho de Grandi”"

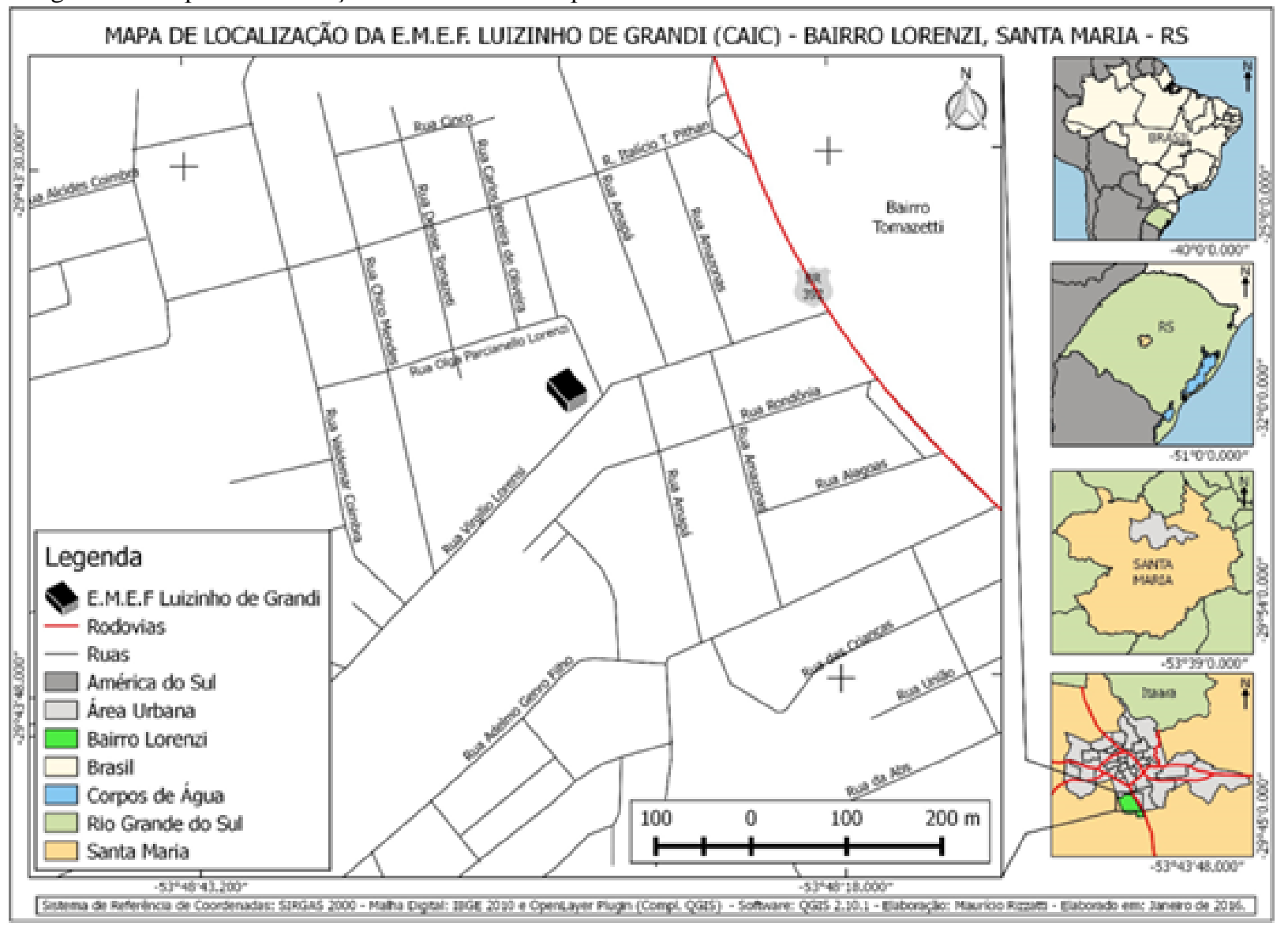

Fonte: Rizzatti, 2016, p. 46.

$\mathrm{Na}$ sequência, apresentam-se as propostas pedagógicas desenvolvidas e os resultados obtidos pelas produções dos estudantes de $7^{\circ}$ anos do Ensino Fundamental. As atividades contribuíram com a discussão ambiental na escola, bem como para a promoção de pesquisas de iniciação científica pelos estudantes de Ensino Fundamental, despertando o interesse pela compreensão da realidade do lugar e pela pesquisa, bem como estimulando o senso crítico e a cidadania.

\section{Ações interdisciplinares sobre o ambiente: relatando a prática na escola}

Para o delineamento metodológico da proposta, primeiramente, foi realizada uma pesquisa prévia sobre os referenciais teóricos da área ambiental para subsidiar o planejamento do trabalho que, inicialmente, foi desenvolvido nas disciplinas de Geografia e de História, em 2016, 
com as turmas de $7^{\circ \text { s }}$ anos, sob o enfoque das doenças virais causadas pelo Aedes aegypti e da cidadania $^{l}$, tema em voga no referido ano devido à significativa presença do mosquito na cidade.

Em 2017, o tema foi ampliado, focando o ambiente de forma mais complexa e agregando a disciplina de Ciências. Assim, quando os alunos dos $7^{\circ}$ anos foram questionados sobre a temática que seria enfatizada na continuidade e ampliação do projeto de ensino, optaram por trabalhar de forma mais enfática com a temática "Ambiente e Reciclagem". Com base nisso, pensou-se uma sequência de práticas que foram desenvolvidas agregando o olhar das disciplinas de Ciências, de Geografia e de História à problemática central: tecnologia, ciência e sustentabilidade aplicadas à Reciclagem.

Para a divulgação do projeto, inicialmente, foi realizado um Concurso de Desenho sobre a temática com o objetivo de sensibilizar e motivar os estudantes para as atividades subsequentes. Os desenhos deveriam contemplar a temática central da proposta, mas tendo a Escola como foco de espacialização das problemáticas. Foram recebidos oito desenhos dos quais se escolheu dois como primeiro e segundo colocados.

Após a divulgação, cada grupo de alunos dos $7^{\circ}$ anos desenvolveu um tema de seu interesse relacionado à temática principal. Com base nos projetos dos alunos, elaboraram-se protótipos dentre os quais se destacam:

a) Reutilização de garrafas PETs para a construção de: Poof; Aspirador de pó caseiro; Ar condicionado; Descansos de panelas (Tampas); Ampulhetas (relógios, cronômetros);

b) Uso de tampas metálicas como base para a elaboração de bolsas com crochê;

c) Confecção de plástico caseiro-biodegradável utilizando batata;

d) Elaboração de Mapa Tátil (Interativo) de localização do município de Santa Maria, RS, com reutilização de materiais plásticos e pensando a inclusão de pessoas cegas;

e) Lâmpada de lava, na qual o óleo utilizado no experimento pode ser reutilizado na elaboração de sabão.

Observa-se que o plástico foi um dos objetos que apresentou maior destaque nas escolhas dos estudantes. Isso se deve ao fato de observarem cotidianamente garrafas plásticas jogadas nas ruas do bairro da Escola e dos bairros onde residem, fato que também auxilia na presença do

\footnotetext{
${ }^{1}$ Mais informações e detalhes acerca da proposta desenvolvida em 2016, na EMEF Junto ao CAIC Luizinho de Grandi, podem ser encontrados no Relato de Experiência "O mosquito Aedes aegypti como tema gerador em atividade interdisciplinar de Geografia e de História no Ensino Fundamental", de Batista e Martins (2017), publicado na Revista de Ensino de Geografia (UFU).
} 
Aedes aegypti. Partindo dessa observação, os estudantes se questionaram sobre a possibilidade de dar um destino mais adequado aos materiais que se encontram em abundância na região e são desperdiçados na medida em que não são reutilizados como matéria-prima para a produção de objetos para uso cotidiano. Além disso, os plásticos são constituídos de polímeros e, desta forma, podem ser moldados com maior facilidade que outros materiais, fato que motivou os alunos a pensarem suas propostas destacando esse recurso reciclável.

Os estudantes também identificaram que plásticos apresentam um número que os identifica, geralmente impresso nas embalagens, para facilitar o processo de separação e reciclagem. Com base nos tipos e características dos plásticos, optaram por trabalhar com os PETs que são os mais encontrados nos bairros onde residem e estudam. O quadro 2 apresenta resumidamente as principais características dos tipos de plástico de acordo com Franchetti e Marconato (2003) e que foram estudados pelos alunos da Escola.

Quadro 2-Características dos tipos de plástico.

\begin{tabular}{|l|l|l|l|l|}
\hline \multicolumn{1}{|c|}{ Tipo de Plástico } & \multicolumn{1}{|c|}{ Sigla } & No & \multicolumn{1}{|c|}{ Características } & \multicolumn{1}{c|}{ Exemplos } \\
\hline Politereftalato de etileno & PET & 1 & $\begin{array}{l}\text { Transparente, inquebrável, } \\
\text { impermeável e leve }\end{array}$ & $\begin{array}{l}\text { Garrafas de água mineral e de } \\
\text { refrigerante }\end{array}$ \\
\hline $\begin{array}{l}\text { Polietileno de alta } \\
\text { densidade }\end{array}$ & PEAD & 2 & $\begin{array}{l}\text { Inquebrável, resistente a baixas } \\
\text { temperaturas, rígido, impermeável e } \\
\text { leve }\end{array}$ & $\begin{array}{l}\text { Sacolas de supermercado e } \\
\text { embalagens de materiais de } \\
\text { limpeza }\end{array}$ \\
\hline Cloreto de Polivinila & PVC & 3 & $\begin{array}{l}\text { Rígido, inquebrável, impermeável e } \\
\text { resistente a temperatura }\end{array}$ & $\begin{array}{l}\text { Canos, forros e filmes para } \\
\text { embalar alimentos }\end{array}$ \\
\hline $\begin{array}{l}\text { Polietileno de baixa } \\
\text { densidade }\end{array}$ & PEBD & 4 & $\begin{array}{l}\text { Transparente, flexível impermeável e } \\
\text { leve }\end{array}$ & $\begin{array}{l}\text { Embalagens de iogurte e de papel } \\
\text { higiênico }\end{array}$ \\
\hline Polipropileno & PP & 5 & $\begin{array}{l}\text { Transparente, inquebrável, conserva o } \\
\text { aroma, brilhante, rígido e resistente a } \\
\text { mudanças de temperatura }\end{array}$ & $\begin{array}{l}\text { Rótulos de refrigerantes e potes } \\
\text { Poliestireno }\end{array}$ \\
\hline
\end{tabular}

Fonte: Franchetti e Marconato, 2003, p. 44.

Toda a discussão sobre o reaproveitamento do plástico na confecção dos produtos produzidos pelos estudantes foi baseada nos cinco "Rs" que, de acordo com Friedrich (2014), são: Reduzir, Reutilizar, Reciclar, Repensar, Responsabilizar. É necessário reduzir a produção de resíduos/lixos, reutilizar ou reaproveitar o material em outra função, reciclar transformando os materiais em novos produtos, repensar a geração de resíduos/lixos e responsabilizar os 
fabricantes e consumidores, no sentido de receber os produtos que foram comercializados (FRIEDRICH, 2014).

Com base nisso, os estudantes produziram os materiais, realizando a pesquisa e adaptação de todas as etapas de confecção sob a orientação das professoras de Ciências, de Geografia e de História. Para a confecção do Poof utilizaram garrafas PETs, pedaço de espuma para o assento, fita adesiva e uma capa de tecido. Para a bolsa e para os descansos de panelas reaproveitaram lacre de latinhas e tampas das garrafas PETs utilizadas no Poof, cola quente e cola do tipo Super Bonder®. Com esses produtos, discutiu-se a possibilidade de fazer objetos baratos e úteis para uso cotidiano de forma que se reaproveite efetivamente o "lixo" encontrado disposto inadequadamente no bairro.

Quanto ao aspirador de pó, construíram-no com uma garrafa PET, fita isolante, arame, tecido, um motor 5 volts (de carrinho à pilha), cola quente, uma fonte elétrica, um interruptor, tubo de desodorante (confecção da hélice), tesoura, canudo de plástico, mangueira plástica e tubo de cola. E o ar condicionado caseiro foi construído com um Cooler (peça de notebook), fita isolante, garrafa PET, tesoura, fonte elétrica, conector (tomada), mangueira e um galão de plástico para armazenamento da água do gelo utilizado na refrigeração do ambiente. Nesta abordagem, além da questão ambiental e do reaproveitamento, discutiram-se conceitos como o de convecção térmica pertinente a Ciências e à Geografia, bem como de deslocamento de ar e forças envolvidas no processo de refrigeração e/ou sucção do pó.

Além dos plásticos tradicionais, apresentou-se a proposta de um material biodegradável: o plástico de batata. Para sua construção utilizaram-se quatro batatas (ricas em amido), três colheres de vinagre (moléculas com ramificações, atrapalham a formação do plástico, o vinagre reage e deixa as moléculas organizadas), duas colheres de Glicerina (para deixar plástico maleável) e corante. A partir disso, pode-se discutir a influência dos microrganismos na degradação dos produtos considerados lixos e contrastar o biodegradável com o convencional que fica por décadas poluindo o ambiente. O plástico de batata foi construído como uma proposta alternativa aos demais tipos de plástico para que os alunos conhecessem esse material biodegradável e vislumbrassem alternativas futuras ao polímero que é tão utilizado na indústria e no cotidiano dos estudantes.

Nesta linha de objetos, fez-se também a lâmpada de lava que reutilizou um litro de óleo de cozinha, um copo de água, corante, comprimidos efervescentes e uma garrafa PET. Com ela, 
discutiram-se as reações químicas e seus subprodutos, destacando, por exemplo, os gases estufa que geram a destruição da camada de ozônio como o subproduto $\mathrm{CO}_{2}$, presente nesta reação, e que foi contextualizando com as práticas humanas que provocam o agravamento do efeito estufa gerando o aquecimento global como a industrialização, os poluentes dos carros, entre outros.

O Mapa Tátil (Interativo) de localização do município de Santa Maria, RS, foi proposto para destacar o contexto de onde os alunos vêm e de onde partiu as suas pesquisas, mas de forma que qualquer pessoa pudesse identificar essa localização. Portanto, ressalta-se a preocupação com o "como o outro percebe o mundo", bem como com a inserção de todas as outras pessoas na discussão ambiental tecida pelos estudantes. Para sua produção, utilizou-se um mapa base, diferentes tipos de rejeitos de papel e traduções em braile (feitas pela Educadora Especial da escola, Professora Maureline Petersen). Por fim, a ampulheta, confeccionada com garrafas PET, um cabo de vassoura e restos de madeira e de areia, foi pensada como uma metáfora, ou seja, o tempo está escoando e cada segundo que não se pensa novas possibilidades para o reaproveitamento de materiais e para um ambiente mais sustentável e saudável, reduz-se as chances de transformar a vida em sociedade e de construir uma "nova ética ambiental".

O mosaico a seguir (Figura 2) apresenta etapas da produção de alguns dos materiais da proposta pedagógica.

Figura 2 - Etapas da produção dos materiais reciclados: (A, B, C) Alunos dos $7^{\circ \mathrm{s}}$ anos produzindo objetos materiais recicláveis, (D) Confecção de Mapa Tátil e (E) Exemplo de objeto produzido: Poof de Garrafas PET.

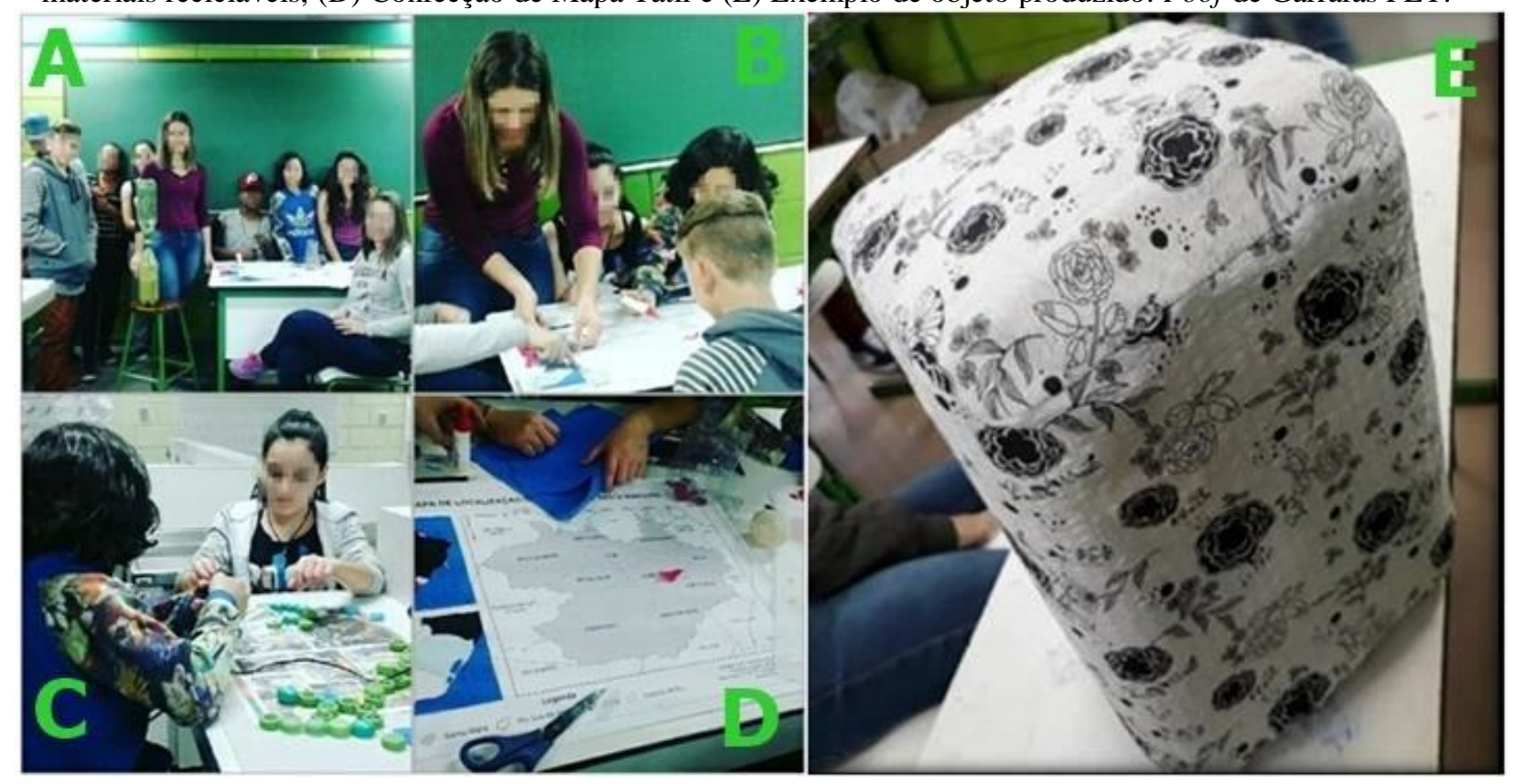

Fonte: Autoras, 2017. 
Em conjunto com a elaboração dos materiais recicláveis os estudantes também produziram uma Peça de Teatro para a divulgação e sensibilização na Escola sobre o ambiente e sobre os produtos confeccionados e também para a disseminação dos conhecimentos construídos. A Peça contou com o apoio de mestrandos (Cristiano Bittencourt Santos e Isis Moraes Zanardi) e de uma Professora (Elsbeth Léia Spode Becker) do Mestrado de Ensino de Humanidades e Linguagens (MEHL), da Universidade Franciscana, bem como com o Grupo de Iniciação ao Canto da Escola (coordenado pela Professora Izane Dalla Nora).

A produção da Pça de Teatro contou com quatro encontros de duas horas cada. No primeiro encontro os alunos trabalharam com expressão corporal, nos segundo e terceiro encontros produziram o texto e realizaram os ensaios e no quarto encontro apresentaram para os demais estudantes da EMEF Junto ao CAIC Luizinho de Grandi, divulgando os materiais reciclados construídos e colaborando com a sensibilização frente à necessidade da Reciclagem no bairro da Escola e bairros circunvizinhos (Figura 3).

Figura 3 - Peça de Teatro para sensibilização ambiental na Escola: (A) abertura da peça com a apresentação Grupo de Iniciação ao Canto, (B) apresentação da Peça de Teatro, (C) divulgação dos materiais recicláveis e (D) apresentação da música final

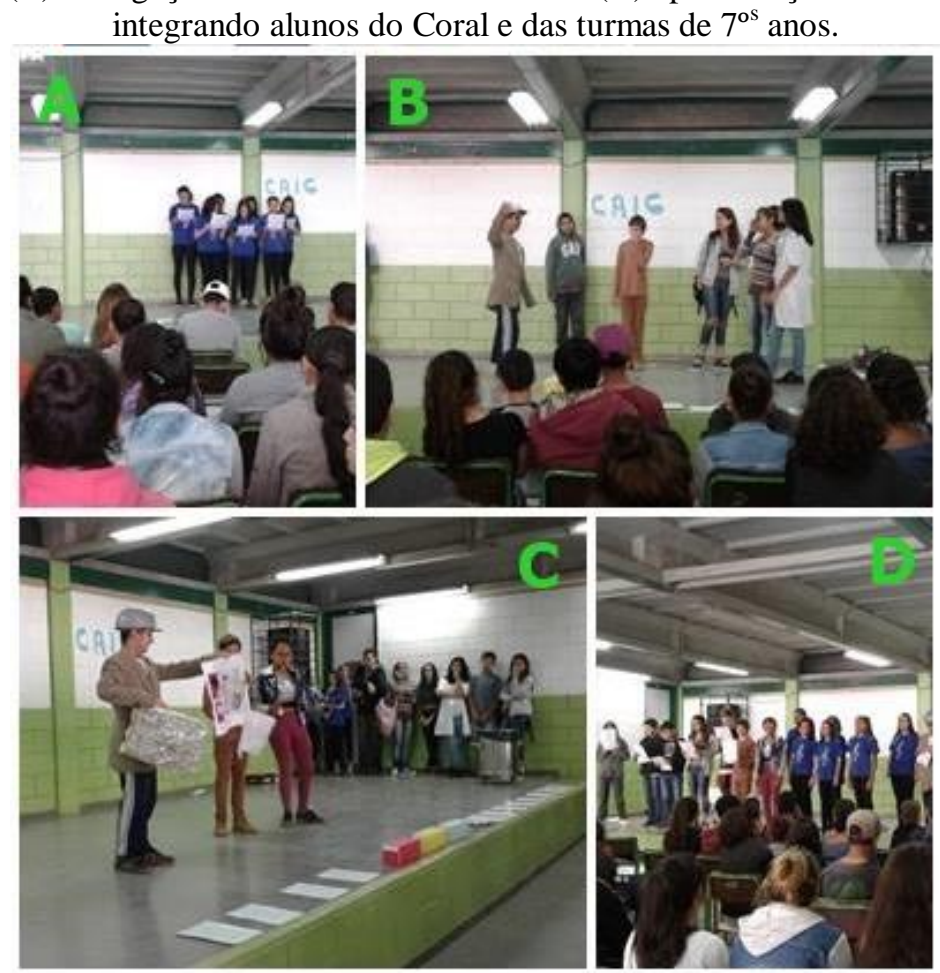

Fonte: Autoras, 2017. 
A Peça de Teatro versou sobre a problemática ambiental na Escola e teve como roteiro o texto a seguir (Quadro 3). É importante destacar que todos os nomes citados são fictícios e escolhidos pelos estudantes, todavia nenhum deles corresponde aos nomes reais dos participantes da proposta.

Quadro 3 - Peça de Teatro produzida pelos alunos da EMEF Junto ao CAIC Luizinho de Grandi

\section{CAIC - Texto dos educandos}

\section{Personagens:}

O senhor da manutenção da escola (limpeza): José

Ajudante: Severino

Alunas: Lindalva e Lara

Professora: Fernanda

Bagunceiros: Robson e Gabriel

Engenheiro Ambiental: Paulo

Narrador

Música: Planeta Água - Guilherme Arantes (Grupo de Iniciação ao Canto)

\section{Cena 1:}

Seu José e Severino estavam a limpar o pátio da escola e conversam.

- José: Por que tem tanto lixo no chão com tantas lixeiras? Você entende isso Severino?

- Severino: Pois é, porque ninguém ajuda a cuidar.

- José: É a vida.

\section{Cena 2:}

Entram duas estudantes em cena.

- Lindalva: Meus Deus, quanta sujeira! Será que não há lixeiras no colégio?

- Lara: Pois é, o seu José está tão idoso que não consegue mais limpar a escola sozinho.

- Lindalva: Tive uma ideia! Vamos fazer um grupo para ajudar a limpar!

- Lara: Mas será que eles vão querer ajudar?

- Lindalva: Não custa tentar.

\section{Cena 3:}

(Bagunceiros entram em cena e escutam a conversa)

- Robson: Ah para! Não vou levantar 10 minutos mais cedo para vim varrer a escola.

- Gabriel: Por que vou perder 20 minutos da minha vida? Se o Severino é pago e não faz mais nada da vida.

(Pausa - entra narrador)

Narrador: No dia seguinte irá acontecer o esperado, ou será que não?

\section{Cena 4:}

José e Severino voltam para o trabalho e nesse momento surge a professora. 
- Professora: Severinoooo! Seu Joséeee! Tenho uma ótima noticia para vocês.

- José: Mais pátio e mais lixo (Fala com desânimo)

- Professora: Notícia é que a Laura e a Lindalva tiveram uma ideia. Elas vão organizar um grupo para ajudar na coleta do lixo.

(Entram as estudantes)

- Lindalva: E boa parte desse lixo vai virar objetos para a nossa escola.

(Surge na cena Paulo, o engenheiro ambiental amigo da professora)

- Paulo: Podemos utilizar o lixo para produzirmos materiais recicláveis.

\section{Cena 5:}

Os demais estudantes entram em cena e ajudam a limpar o pátio e a colocar o lixo nos lugares corretos.

- Paulo: Latinha aqui, orgânico ali, vidro lá! (coletores de lixo reciclável)

Música: O que é, o que é? - Gonzaguinha (Grupo de Iniciação ao Canto, fundo para a limpeza do pátio cênico).

\section{Cena 6:}

Volta os bagunceiros

- Robson: Poxa, funcionou e a gente se ferrou!

- Gabriel: Parece que ainda dá tempo de ajudarmos.

(Volta o narrador)

- Narrador: E assim termina nossa história! Mas espere um minutinho! Veja o que estamos produzindo com o lixo reciclável.

(Entram os materiais construídos pelos alunos)

Música: Aquarela do Brasil - Toquinho (Grupo de Iniciação ao Canto e estudantes do $7^{\circ}$ ano)

\section{Final:}

Todos se organizam de frente para o público e dizem:

\section{REDUZA, RECICLE E COPIE ESSA IDEIA TAMBÉM!}

Fonte: Produção dos alunos de $7^{\circ s}$ anos da EMEF Junto ao CAIC Luizinho de Grandi, 2017.

A Peça de Teatro contextualizou um problema observado pelos alunos no pátio da Escola e no bairro, propondo uma solução viável e que busca transformar a realidade a partir de ações simples, eficientes e cotidianas que emergem em um contexto de busca de soluções sustentáveis, envolvendo a comunidade escolar o que repercute na comunidade geral.

Todas as produções foram organizadas e expostas na III Feira Municipal de Ciência, Tecnologia e Sustentabilidade (Figura 4). Na feira, os quarenta e sete trabalhos expostos foram avaliadas pelos critérios: comunicação do trabalho, domínio do conteúdo envolvido, originalidade, qualidade científica, relevância científico-socioambiental, inovação, empreendedorismo, cooperatividade e solidariedade. Com base nesses critérios o trabalho foi 
premiado em $3^{\circ}$ Lugar na categoria Anos Finais. Todavia, a maior premiação foi o envolvimento e motivação dos estudantes na produção de conhecimentos para a resolução de um problema local o que despertou a criatividade, o espírito de equipe e a colaboração entre eles.

Figura 4 - III Feira Municipal de Ciência, Tecnologia e Sustentabilidade realizada pela Prefeitura Municipal de Santa Maria: (A, B e C) alunos com os objetos construídos a partir de materiais recicláveis e (D) Premiação da

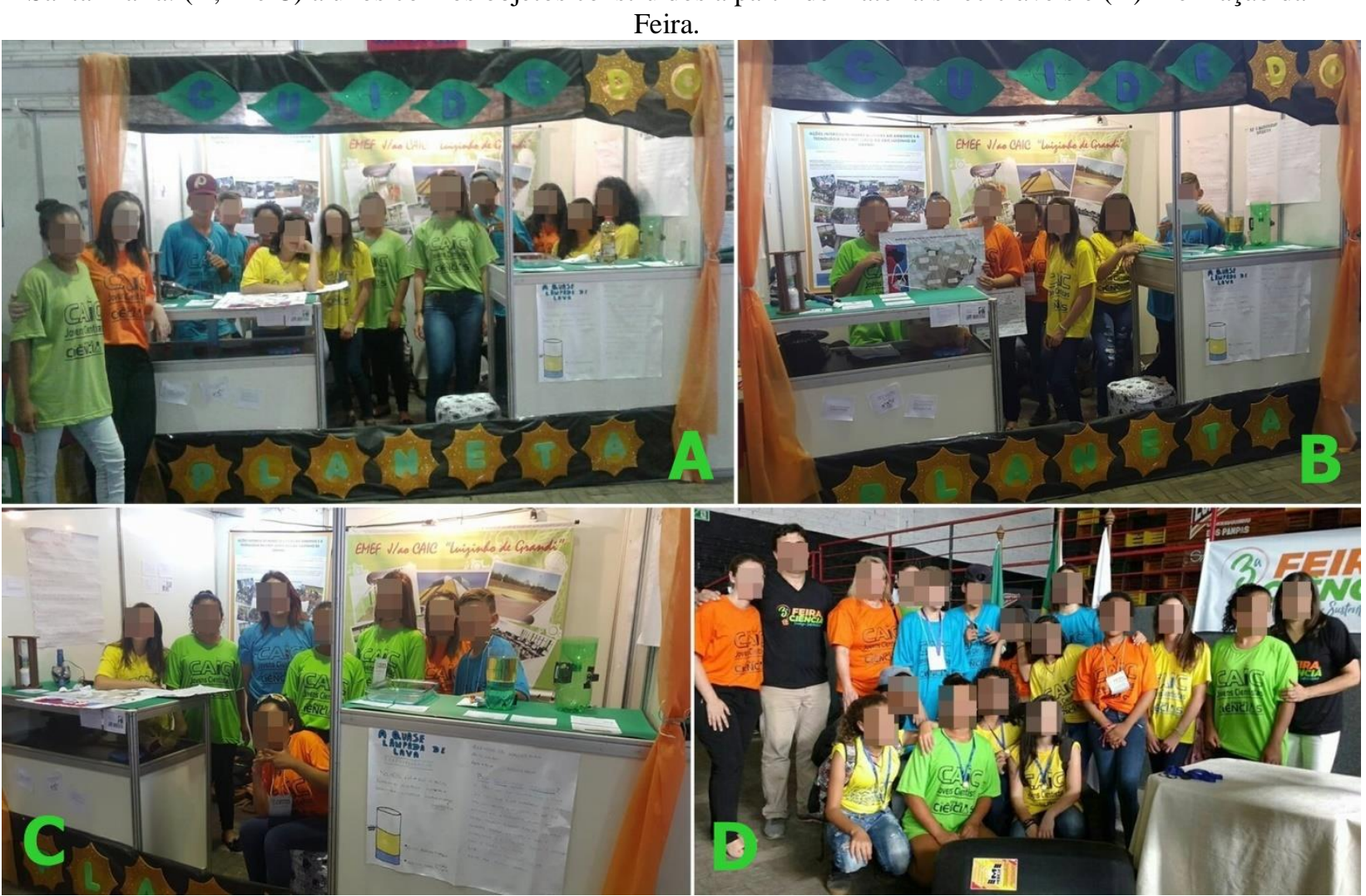

Fonte: Autoras, 2017.

Destaca-se que a sequência pedagógica desenvolvida trabalhou na perspectiva de uma Educação Ambiental crítica, pois envolveu os alunos não somente na produção e exibição dos materiais recicláveis, mas destacou a coleta seletiva e recolhimento de lixo para a produção de produtos, a contextualização da problemática no bairro, a sensibilização de outros estudantes frente à temática, o olhar global frente à questão do lixo, entre outros aspectos. Pensou-se a Reciclagem como algo necessário e possível de serem realizadas nas práticas cotidianas dos alunos, familiares, professores, funcionários, enfim, dos envolvidos na proposta.

Assim, trabalhou-se com as quatro dimensões da sustentabilidade porque destacou a visão: 
a) Ecológica: ao trabalhar com a possibilidade de microrganismos decomporem os produtos, bem como ao evidenciar os impactos do lixo nos ecossistemas locais;

b) Econômica: produzindo materiais que reutilizam produtos e que podem gerar renda as famílias e aos alunos, se confeccionados com essa finalidade, bem como propõem formas de produção alternativas às convencionais;

c) Política: destacando a responsabilização dos sujeitos pela qualidade de vida e pelo futuro do lugar onde vivem e do Planeta, bem como os fazendo atuarem como multiplicadores do saber ambiental construído;

d) Social: pois assegura o acesso aos bens produzidos e a qualidade ambiental resultante de uma prática sustentável.

Assim, a Educação Ambiental deve enfatizar ideais capazes de promover espaços de formação para a apropriação de novas ferramentas, novas metodologias de ensino e novos conhecimentos, a fim de incluir a comunidade em contextos geográficos e temporais específicos, promovendo novos saberes e novos modos de agir frente ao mundo em que vivemos (BATISTA; ZIEMANN; PRINA, 2018). Neste sentido, “A Educação Ambiental passa, portanto, a constituir um direito do cidadão, assemelhado aos direitos fundamentais, estreitamente ligados aos direitos e deveres constitucionais da cidadania" (DOTTO, 2016, p. 22) e pode proporcionar uma reflexão coletiva frente à realidade ambiental local.

\section{Conclusão}

Com base nas observações durante o desenvolvimento das atividades, pode-se perceber que os alunos se sentiram motivados com a realização da proposta em todas as suas etapas, atuando como jovens pesquisadores e sendo autônomos na construção de seus conhecimentos. Além disso, o trabalho interdisciplinar frente à temática ambiental fez com que pudessem ampliar o seu entendimento sobre os seus temas de interesse, despertando o espírito de colaboração e cooperativismo na produção de conhecimentos científicos e socioambientais.

Ressalta-se também que o trabalho contribuiu com a discussão ambiental na Escola de forma efetiva, consciente, articulada e interdisciplinar, bem como empreendeu a possibilidade da realização de pesquisas de iniciação científica pelos estudantes de Ensino Fundamental, versando sobre o seu espaço de vivência, sobre o ambiente e sobre novas perspectivas de produção 
voltadas a um mundo sustentável sob os olhares das disciplinas de Ciências, Geografia e História. Portanto, o trabalho desenvolvido permitiu discutir um tema relevante com base no contexto local e de forma interdisciplinar, estimulando a autonomia, o pensar crítico, a criatividade e a intervenção dos alunos na comunidade em que residem e na Escola em que estudam, mostrando-se eficiente e atingindo os objetivos propostos pelas Autoras/Professoras da Escola.

\title{
5 Agradecimentos
}

Agradecemos aos colegas da EMEF Junto ao CAIC Luizinho de Grandi que auxiliaram das mais diversas formas e nos diferentes momentos do trabalho, aos mestrandos Cristiano Bittencourt Santos e Isis Moraes Zanardi e à professora Elsbeth Léia Spode Becker do Mestrado de Ensino de Humanidades e Linguagens (MEHL), da Universidade Franciscana (UFN), e ao Grupo de Iniciação ao Canto, coordenado pela Professora Izane Dalla Nora, pelo apoio na realização da Peça de Teatro, bem como as empresas locais que doaram produtos para a realização de uma rifa para custear as camisetas, os lanches e o transporte para os estudantes participarem da III Feira Municipal de Ciência, Tecnologia e Sustentabilidade.

\section{ENVIRONMENTAL EDUCATION, SUSTAINABILITY AND RECYCLING: REPORT OF A PEDAGOGICAL EXPERIENCE CONDUCTED WITH STUDENTS OF FUNDAMENTAL TEACHING}

\begin{abstract}
Environmental Education appears with the possibility of a new look on the world and, consequently, as a form of interdisciplinary debate about the realities and the programmatic content sof the different disciplines. From this, the article has as general objective to report interdisciplinary practices developed in the disciplines of Sciences, Geography and History, in relation to the environmental theme related to reusable, inclusive and interactive technologies. Basedon these premises, the students of the 7th year, of EMEF Junto ao CAIC Luizinho de Grandi, developed research related to technology, science and sustainability applied to recycling and built materials that were exhibited and awarded (3rd place) in the III Municipal Science, Technology and Sustainability Fair held by the City Hall of Santa Maria/RS in the year 2017. The activities developed contributed to the environmental discussion in the school, as well as to the promotion of research of scientific initiation by the students of Elementary Education, arousing the interest for the understanding of the reality of the place and the research, as well as stimulating the critical sense and the citizenship.
\end{abstract}


Keywords: Science. Interdisciplinarity. Environment. Technology. Sustainability. Recycling.

\section{Referências}

BATISTA, N. L; ZIEMANN, D. R; PRINA, B. Z. Por uma Educação Ambiental do Cone Sul: considerações preliminares. Okara: Geografia em Debate (UFPB), v. 12, 1, p. 161-175, 2018.

BATISTA, N. L; MARTINS, L. L. G. O mosquito Aedes aegypti como tema gerador em atividade interdisciplinar de Geografia e de História no Ensino Fundamental. Revista de Ensino de Geografia (UFU), v. 8, p. 244-251, 2017.

BRASIL, Ministério da Educação e Cultura. Secretaria da Educação. Diretrizes Curriculares Nacionais para a Educação Ambiental. MEC/SEF; 2012.

BOFF, L. A águia e a galinha, a metáfora da condição humana. 40ª ed. Petrópolis, RJ: Vozes, 2004.

DOTTO, D. C. O uso de jogos de RPG na gestão de conflitos socioambientais e proteção do geopatrimônio hídrico no município de Itaara /RS. (Dissertação de Mestrado). Programa de Pós-Graduação em Geografia. Santa Maria: Universidade Federal de Santa Maria, 2016.

FERREIRA, M; WORTMANN, M. PCNs e as Orientações para a mudança no Ensino de Química. Anais da 30 ${ }^{\text {a }}$ Reunião Anual da Sociedade Brasileira de Química. Águas de Lindóia, São Paulo, 2007.

FRANCHETTI, S. M. M; MARCONATO, J. C. A importância das propriedades físicas dos polímeros na reciclagem. Química Nova na Escola. n. 18, p. 42-45, Nov. 2003.

FRIEDRICH, L. S. O Lixo Eletrônico como Possibilidade para o Ensino de Química na Formação de Professores. 2014. Dissertação (Mestrado em Educação em Ciências: Química da Vida e Saúde) - Universidade Federal de Santa Maria, Santa Maria, 2014.

GAUDIANO, E. G. Educação Ambiental. Lisboa: Stória Editores, 2005.

JUNGES, J. R. (Bio)Ética Ambiental. São Leopoldo, RS: Editora Unisinos, 2010.

NOVO, M. El Desarrollo Sostenible. Sudimensión ambiental y educativa. Madrid: MCGraw Hill, 2007.

RIZZATTI, M. Cartografia Escolar, geotecnologias e a Teoria das Inteligências Múltiplas: a construção de conhecimentos geográficos no ensino fundamental (Trabalho de Graduação). Universidade Federal de Santa Maria, Centro de Ciências Naturais e Exatas, Departamento de Geociências, Curso de Geografia - Licenciatura Plena, RS, 2016.

ROSSI, A. V; TERCI, D. B. L; TERRA, J; PINHEIRO, T. A. L. Separando e identificando alguns plásticos. Grupo de Pesquisas em Química Analítica e Educação. IQ-UNICAMP: 2005. 